\title{
Resenha da obra "Mente, Homem e Máquina” de Paul T. Sagal à luz das teorias da Filosofia da Mente
}

\author{
Sérgio Paulo Maravilhas Lopes *
}

recebido: 07/2013

aprovado: 09/2013

Resumo: Analisamos esta obra como sugestão para o início do estudo da temática sobre a Filosofia da Mente. A escolha residiu no facto de se tratar de uma introdução ao estudo do tema, passivel de ser abordada por alunos do ensino préuniversitário, apoiados pelo Professor da disciplina de Introdução à Filosofia. O Docente pode aproveitar algumas vantagens da obra, nomeadamente a sua forma em diálogo, de tipo platónico, que contribui para ajudar o leitor a ser iniciado no tema e a ser cativado para continuar a leitura. Possui algum nível de dificuldade conceptual, de origem filosófica, matemática e lógica, minimizada pela linguagem utilizada pelo autor, bastante ao nível dos alunos préuniversitários (computadores que jogam xadrez, 'Big Mac' ao almoço, etc.). Procuramos proceder à relação entre o que apreendemos na leitura da obra e sua análise e aquilo que poderemos ensinar aos nossos alunos.

Palavras-chave: Filosofia da Mente, diálogo platónicosocrático, argumentação, mecanicismo, máquinas pensantes

Abstract: We analyze this work as a suggestion for the beginning of the study of the subject on the Philosophy of Mind. The choice lay in the fact that it is an introduction to the study of the subject, which can be approached by students of pre-university education, supported by the Teacher of Introduction to Philosophy. The Teacher can enjoy some advantages of the work, including the dialogue format, Platonic type, which contributes to help the reader to be started on the topic and be captivated to continue reading. Has some level of conceptual difficulty of philosophical, mathematical and logical origin, minimized by the language

\footnotetext{
* Ph.D. Licenciado em Filosofia, Mestre em Gestão da Informação e Doutorado em Informação e Comunicação em Plataformas Digitais. Investigador do CETAC.MEDIA - Centro de Estudos das Tecnologias e Ciências da Comunicação da Universidade do Porto e Universidade de Aveiro.
} 
used by the author, quite to the level of pre-university students (chess-playing computers, 'Big Mac' at lunch, etc.). We seek to make the connection between what we learn in reading and analyzing the work and what we can teach to our students.

Keywords: Philosophy of Mind, Socratic-Platonic dialogue, argumentation, mechanism, thinking machines

\section{Introdução}

A escolha desta obra como base para o início do estudo da temática sobre a Filosofia da Mente, reside no facto de se tratar de uma introdução ao estudo do tema, passível de ser abordada por alunos do ensino pré-universitário, desde que apoiados pelo Professor da disciplina de Introdução à Filosofia, quer na entrada da problemática tratada, quer como apoio da terminologia filosófico-científica que lhe está inerente.

Poderá assim o Docente aproveitar algumas vantagens da obra, nomeadamente a sua forma em diálogo, de índole platónica, que em muito contribui para ajudar o leitor iniciado no tema a ser cativado para continuar a leitura e não desistir assim que se veja confrontado com as primeiras dificuldades expositivas e conceptuais, algumas das quais de origem matemática e lógica, bem como a linguagem utilizada bastante ao nível dos alunos na faixa etária em que se encontram e às suas vivências quotidianas (exemplo: computadores que jogam xadrez, 'Big Mac' ao almoço, etc.).

Outra das razões da escolha desta obra, prende-se com o facto de não existirem muitas obras introdutórias da problemática tratada traduzidas para Português, o que se revela sem dúvida uma limitação para aqueles que desejem continuar a sua pesquisa mas não disponham de conhecimentos aprofundados da língua Inglesa que é maioritariamente a origem dos autores e respetivas obras. Achamos, por isso, que este livro poderia ser o primeiro passo, compreensível, para depois se 
poderem aventurar noutras obras mais complexas, essas sim já disponíveis em Português, como "A mente virtual" de Penrose ou "Gödel, Escher e Bach" de Hofstadter entre outras de Putnam, Searle e Rorty.

Procuramos na elaboração desta resenha proceder à relação entre o que apreendemos na leitura da obra e sua análise e aquilo que poderemos ensinar aos nossos futuros alunos, bem como à forma de os cativar para a leitura e para a vontade de querer saber cada vez mais e sobre os mais diversos assuntos dentro das várias áreas do saber humano. Essa é outra das razões da escolha deste livro para analisar.

Assim, para mais facilmente podermos avaliar os benefícios que a referida obra pode ter para o desempenho das nossas funções Docentes e para o deleite dos nossos jovens alunos, passaremos a tecer algumas considerações, de forma resumida, acerca dos pontos mais importantes que aí são discutidos, tentando sempre que possível remetê-los para os autores e problemas desenvolvidos na temática em análise.

\section{Estrutura da obra}

A obra, em forma de diálogo, conta com três personagens que a animam em discussões científico-filosóficas relativas, nomeadamente, ao problema da mente/corpo, se podem as máquinas pensar e as várias problemáticas abordadas mais recentemente pelos Filósofos da Mente, sem que por vezes estas sejam nomeadas ou mencionadas direta e objetivamente, mas que se encontram impregnadas no animado debate e nas várias defesas e ataques que nela são elaborados. As três personagens são:

1. FIL - um Filósofo e Professor de Filosofia.

2. EST - um jovem estudante de Matemática.

3. MAT- um Professor de Matemática, que será o auxílio 
do seu aluno no decorrer do debate (cabe notar aqui algumas semelhanças com o "diálogo dos dois grandes sistemas do Mundo" de Galileu, quer quanto à estrutura dialogada, quer quanto ao número de personagens e à função que elas representam na trama).

O corpo da obra divide-se em três dias de discussões, sendo o último dia dividido em outras duas etapas, dada a dificuldade de 'digestão' de todos os temas abordados, e usamos o termo 'digestão' na medida em que o próprio autor denomina a última parte como "Depois de almoço", onde somos confrontados com a dura constatação de que ninguém dispõe de uma certeza absoluta relativamente aos temas tratados, pois de facto onde deveriam existir verdades e certezas, encontramos apenas teorias e especulações, restando aos personagens a vantagem admitida de pelo menos todos terem ficado a saber mais após o debate do que anteriormente ao respetivo confronto de ideias e de posições, numa clara alusão pelo autor à necessidade do diálogo como forma de aprofundar a verdade e o conhecimento de que dispomos. Mais uma vez a indelével marca socrático-platónica a fazer-se sentir. Mas voltemos à obra.

\section{Ideias desenvolvidas e descrição do debate}

Tudo começa com a chegada de EST de uma sessão de um torneio de xadrez, tendo este sido derrotado pelo computador Fischkov III. Se é certo que ninguém gosta de perder, EST sente-se ainda mais desgostoso por ter sido frente a uma máquina. Nas suas lamentações, EST coloca a questão de saber como pode ter ele perdido frente a uma máquina que segundo ele "nem sequer pode pensar". É este o mote que irá dominar o debate do primeiro dia entre EST e FIL, tentando FIL saber porque motivo acha EST que as máquinas não podem pensar, 
explorando vários exemplos animais e tecnológicos tentando desconstruir, 'a la Turing', o antropocentrismo que de uma forma natural instintivamente nos leva a atribuir pensamento racional aos membros da nossa espécie, quase exclusivamente. Nas várias tentativas de chegarem a um acordo quanto ao que parece querer significar 'pensar' e quem será dotado dessa faculdade, várias perspetivas se nos deparam vindas de EST que caracteriza o pensamento como sendo uma conversa interior, processos que acompanham essa conversa tais como conceptualizar e raciocinar, agir segundo planos e com objetivos estratégicos usando táticas que nos permitam alcançar determinado fim, acabando est por admitir que "em certo sentido" as máquinas podem pensar, mas que "nós somos pensadores versáteis", pois o nosso pensamento relaciona-se com várias áreas e a capacidade para pensar, de que nós dispomos, exige um comportamento extremamente complexo.

Somos aqui introduzidos por FIL no jogo da imitação de Turing como tentativa de encontrar uma forma de definir e atribuir a algo a capacidade de pensar. A pergunta crucial é, no entanto, colocada por EST: "existe alguma máquina que consiga ganhar o jogo da imitação?" Isso, conforme lhe responde FIL só o futuro nos dirá. Refutações de EST envolvem as já famosas respostas "imitar não é ser" e "o pensamento tem sempre um objetivo", antevendo já o leitor a envolvência no problema da intencionalidade. Passamos pelo 'behaviourismo' e por um argumento em forma de silogismo formulado por EST para rebater a possibilidade das máquinas poderem pensar, argumento esse que é facilmente rebatido por FIL. Outra possibilidade abordada superficialmente diz respeito à questão de até onde devemos descer na escala evolutiva e ontológica para podermos reportar existir vida e consequentemente consciência e possibilidade de pensamento.

Vendo-se sem respostas e notando a desigualdade de 
condições entre ele, um mero estudante e o seu opositor, fica combinado para o dia seguinte um novo debate, desta vez contando EST com o apoio de um seu Professor que "não é simpatizante do mecanismo", servindo este estratagema para terminar o primeiro dia de confronto intelectual e também para engenhosamente introduzir a terceira personagem.

Entramos no segundo dia e com ele MAT que após acusar FIL de poder ser bastante rude, também o alerta de que não é o dono da verdade ("e até aposto que muitos filósofos discordam de ti"). MAT apresenta um novo argumento para discussão, avisando o leitor desprevenido de que o seu argumento exige "a compreensão de um resultado lógico-matemático conhecido por Teorema de Gödel, uma das grandes descobertas científicas do séc. XX". Somos assim confrontados com um argumento que realmente levanta algumas dificuldades aos defensores da Inteligência Artificial forte, não sem antes, a título de propedêutica, nos ser fornecida uma tese que permitirá estabelecer a distinção entre "mecânico" e "sistema físico". "Não é um teorema lógico-matemático, mas antes uma tese (...). Esta tese é conhecida como a "tese de Church"'. Esta tese servirá a MAT como princípio de ligação para que seja possível efetivamente relacionar "a nossa noção intuitiva de máquina com a noção de Gödel de sistemas ou teorias formais". No entanto, conforme constata MAT, esse "princípio de ligação tem de ter um pé na Lógica Matemática e outro na Filosofia ou na Psicologia".

Após uma exaustiva demonstração por parte de MAT da tese denominada argumento Gödel-Church-Lucas, parece ficar demonstrada a impossibilidade de um sistema formal ser simultaneamente completo e consistente, finalizando com a questão a FIL "dado este resultado, suponho que já estás a ver qual vai ser o próximo passo do argumento", respondendo-lhe o seu opositor que necessita de algum tempo para rever o argumento de Gödel, defendendo-se com a escapatória "sabes 
que nós, Filósofos, não vemos muitas vezes argumentos apresentados desta forma", mostrando-se espantado por lhe ter sido apresentado o "argumento de Gödel como uma refutação do mecanicismo". Finda assim o segundo dia de discussão, a fim de que FIL se prepare convenientemente para o "confronto final'.

O terceiro dia inicia-se com uma recapitulação do argumento de Gödel, usado no dia anterior para refutar o mecanicismo (homem=máquina). MAT após apresentar o seu "calcanhar de Aquiles do mecanicismo" continua dizendo que "somos diferentes das máquinas; somos superiores em pelo menos um aspeto: podemos identificar algumas verdades que as máquinas não podem" - as da aritmética e da sua "interpretação codificada".

Com o avançar do diálogo e das sucessivas refutações por parte de FIL, nomeadamente onde reside a diferença entre um ser vivo e um objeto inanimado, bem como onde se estabelece a passagem de ser vivo a autoconsciente, sem o recurso a argumentos matemáticos, mas somente às frases de Gödel por serem autorreferenciais, MAT acaba por desabafar que não sabe bem como reagir e que "os Filósofos têm uma reputação bem merecida de confundirem as pessoas". $\mathrm{Na}$ sua contraargumentação, FIL remete-nos agora para a demonstrabilidade inerente às máquinas, ao contrário da justificação que para nós humanos é suficiente. Daí à 'Teoria semântica da verdade' de Tarski é apenas um pequeno passo, mostrando a MAT a inconsistência das frases de Tarski, uma vez que essas "são verdadeiras se e só se são falsas e vice-versa, contornando e invertendo o problema até inferir que "por isso, não acabará o argumento de Gödel-Church-Lucas por demonstrar a nossa inferioridade em relação aos robôs, em vez de demonstrar a nossa superioridade em relação a eles". Com este desfecho é que MAT não contava e pede a FIL que tenha pena dele e o deixe ir a "casa tomar umas aspirinas" e que depois, quando a 
sua "cabeça ficar mais clara" regressará para "voltar a ser castigado", esperando concretizar o sonho de "virar o feitiço contra o feiticeiro".

O diálogo prossegue "quatro horas depois" com um renovar da confiança de MAT. Volta-se à discussão acerca da validade da tese de Church como sendo, segundo MAT, "uma explicação precisa do conceito intuitivo de 'processo mecânico", que assim é explicado "em termos de noções matemáticas, tais como sistemas formais e máquinas de Turing". Outra tese, a de Kleene-Post a respeito dos sistemas formais é introduzida como sendo equivalente à de Church acerca da recursividade e à de Turing, relativamente à sua máquina virtual. No entanto, MAT admite "que nunca será possível demonstrar que uma noção intuitiva como a de um processo mecânico é equivalente a uma expressão matemática precisa, expressa em termos de máquina de Turing ou de sistemas formais".

Prosseguimos agora com a afirmação de FIL de que no fundo, nós, seres humanos, somos a "realização em carne e osso de máquinas de Turing", remetendo-nos novamente para o problema mente/corpo, mas desta vez discutido com MAT e não com EST como aconteceu no primeiro dia de discussão. Continua FIL, empreendendo agora um argumento a respeito do Funcionalismo de Putnam, descrevendo o seu raciocínio usado em 'Minds and Machines', estabelecendo a correspondência entre "estados lógicos ou de programação e os nossos estados mentais". É aqui que, ante a promessa de um ataque com um argumento menos matemático por parte de MAT, FIL propõe um intervalo para almoço, convidando os seus interlocutores para um "Big Mac" (expressão usada pelo autor no texto, em inglês na versão portuguesa), após o qual combinam "voltar a atacar o problema".

Depois do almoço e com um novo vigor intelectual proporcionado, sem dúvida, pela ingestão do seu 'Big Mac', 
MAT começa por referir que o "pensamento humano não é formal, não é finito e definido. O pensamento humano é intuitivo, informal e autoconsciente", uma vez que podemos "compreender totalidades", algo que nenhuma máquina consegue fazer, pois "nunca poderemos dizer com propriedade que as máquinas, enquanto realizações de sistemas formais, compreendem seja o que for". MAT faz agora apelo a um exemplo de um polícia de trânsito robô que é uma réplica do argumento do 'Quarto Chinês' de Searle, mostrando que essa máquina "não compreende seja o que for porque carece de intencionalidade, essa característica de certos estados mentais pela qual são direcionados para objetos e estados de coisas no mundo". De salientar uma exacerbada tendência behaviourista por parte de FIL, criticada e muito bem por MAT. De argumento em argumento (apelando até à autoridade de Aristóteles e de S. Tomás de Aquino), somos chegados a um novo argumento em que MAT se apoiará para, mais uma vez, fazer valer a sua posição. Trata-se do argumento de Jackson denominado de 'Mary' a neurocientista, que aqui aparece no seguimento da tese da verdade acerca de frases declarativas de Russell.

Adiante, FIL recorre ao exemplo fisicalista da dor como sendo o resultado do estímulo das fibras no cérebro. MAT riposta, desta vez apelando à ciência e algumas das suas descobertas. Filosofia da Ciência, Moral, Kant, Newton e Einstein sucedem-se a um ritmo vertiginoso, procurando Fil evitar a discussão acerca do livre arbítrio, referindo "mas porque havemos de mexer onde não nos dói", até chegarmos ao derradeiro argumento de FIL, que deriva de um argumento de Michael Scriven, em alguns aspectos semelhante ao jogo da imitação.

\section{Conclusão}


Tratando-se de um diálogo de tipo platónico-socrático, este não poderia terminar de outra forma que não fosse sem uma conclusão ou acordo na linha do horizonte, incluindo mesmo o autor uma fala de MAT que traduz exatamente o sentimento que descreviam os interlocutores de Sócrates, o moscardo, quando utilizava a sua ironia e maiêutica. Assim, "por outras palavras, agora não sei se a minha posição está errada e a tua certa. O que sei é que, afinal, não sabia o que pensava saber". E continua "o que me confunde de alguma maneira é o facto de me teres conduzido a este estado sem que tu próprio saibas qual é a posição correta sobre o problema homem/máquina", ao que FIL lhe responde "tens, sem dúvida, razão quando dizes que não sei qual é a posição correta (...). Se sei alguma coisa (...), consiste em como fazer perguntas e como argumentar, como aduzir razões a favor e contra diversas posições", mostrando-nos que o papel da Filosofia e do Filósofo, no fundo, não é encontrar respostas, mas sim ir seguindo uma linha de raciocínio e questionação que nos permita ir ascendendo no nosso próprio conhecimento acerca do problema a enfrentar, pois o papel da Filosofia é precisamente esse desbravar de novos caminhos que conduzam à progressão do conhecimento.

A jeito de conclusão, de referir que o interesse principal desta obra talvez resida nessa lição de que a Filosofia e os seus métodos são sempre atuais, uma vez que os problemas velhos de mais de dois mil anos persistem, mudando-se a roupagem, disfarçando-se com novos nomes e enfeitados com novas teorias, se calhar para não constatarmos a nossa ignorância e impossibilidade de os resolver, mas afinal, de verdadeiro e certo, nada sabemos e, porventura, nunca viremos a saber.

\section{Referências bibliográficas}

CHURCHLAND, P.; CHURCHLAND, P. "Could a machine think?" In: Scientific American 262. 1. 32-39. 1990. 
HOFSTADTER, D. Gödel, Escher, Bach: Laços Eternos. Lisboa: Gradiva. 2000.

PENROSE, R. A Mente Virtual: Sobre computadores, mentes e as leis da fisica. Lisboa: Gradiva. 1997.

PUTNAM, H. "Minds and Machines". In: Dimensions of Mind, ed. Sidney Hook. New York: New York University Press. 148-180. Repr. in Mind, Language and Reality (1975). 362-385. 1960.

PUTnAM, H. Mind, Language and Reality. Philosophical Papers. Vol. 2. Cambridge: Cambridge University Press. 1975.

PUTNAM, H. Pragmatism: An Open Question. Wiley. 1994.

QUINE, W. Filosofia e Linguagem. Porto: Asa. 1995.

SEARLE, J. Intentionality: An Essay in the Philosophy Of Mind. Cambridge University Press. 1983a.

SEARLE, J. "Can Computers Think?” In: Chalmers, D. Philosophy of Mind: Classical and Contemporary Readings, Oxford: Oxford University Press. 669-675. 1983b.

SEARLE, J. A Redescoberta da Mente. Instituto Piaget. 1998.

SEARLE, J. Mente, Cérebro e Ciência. Lisboa: Edições 70. 2000.

TURING, A. "Computing Machinery and Intelligence". In: Mind. 49. 236. 433-460. 1950. 